\title{
TESTES DE BOMBEAMENTO COMO REQUISITOS PARA ELABORAÇÃO DE MODELOS HIDROGEOLÓGICOS CONCEITUAIS: ESTUDO DE CASO NO AQUÍFERO SERRA GERAL
}

Filipe Montanheiro $^{1 ;}$ Elias Hideo Teramoto $^{1}$; Bruno Zanon Engelbrecht ${ }^{1}$; Chang Hung Kiang ${ }^{1}$

\section{RESUMO}

Embora represente um importante reservatório de água subterrânea com significativa abrangência regional, as características e parâmetros hidráulicos dos aquíferos da Formação Serra Geral não são bem compreendidos. O presente trabalho demonstra a importância da aplicação de testes de bombeamento como subsídio ao aprimoramento de modelos hidrogeológicos conceituais, bem como de se monitorar dois poços simultaneamente durante o teste de bombeamento, priorizando a análise derivativa para eliminação de ambiguidades durante a interpretação dos mesmos. Os resultados obtidos indicam que analisar apenas o rebaixamento do poço bombeado pode induzir a interpretações equivocadas. As sucessivas tentativas de se ajustar as diversas soluções aos resultados do teste de bombeamento, mostram que o Aquífero Serra Geral neste ponto de Campina Verde/MG é do tipo confinado drenante, concordante com um modelo geológico de sucessão de derrames de lavas.

Palavras-Chave: Teste de Bombeamento; Modelo hidrogeológico, Aquífero Serra Geral.

\footnotetext{
${ }^{1}$ LEBAC - Laboratório de Estudos de Bacia

UNESP - Universidade Estadual Paulista "Júlio de Mesquita Filho"

Endereço: Avenida 24A, 1515, Bairro Bela Vista, 13506-900 - Rio Claro/SP

Fone: (19) 3526-9310 e (19) 3526-9453
} 


\begin{abstract}
Although the groundwater represents an important and significant regional reservoir, the characteristics and hydraulic parameters of the Serra Geral Formation aquifers are not well understood. This study aims to demonstrate the importance of applying aquifer tests as subsidy to the improvement of conceptual hydrogeological models and the importance of monitoring two wells simultaneously during the pumping test, giving priority to derivative analysis to eliminate ambiguities in the interpretation. The obtained results indicated that the analysis of drawdown of the pumped well could lead to misinterpretations. Successive attempts to adjust different solutions to the pumping test results indicated that the Serra Geral Aquifer in the study area is a leaky confined aquifer type, in agreement with a geological model of succession of lava flows.
\end{abstract}

Key-Words: Pumping test; Hydrogeological Model, Serra Geral Aquifer. 


\section{INTRODUÇÃO}

Os derrames de lavas basálticas da Formação Serra Geral representam uma das maiores manifestações vulcânicas episódicas de caráter básico do Neocomiano com uma espessura total de até $2.000 \mathrm{~m}$ de basalto sobre os sedimentos da Bacia do Paraná, sendo principalmente representadas por derrames de natureza básica e subordinadamente por rochas ácidas.

Estas rochas acumulam águas subterrâneas no que se configura o denominado Aquífero Serra Geral, onde a circulação e o armazenamento estão condicionados, principalmente, pela estratificação basáltica gerada por diferentes eventos magmáticos e resfriamento heterogêneos das lavas (LASTORIA et al, 2010). Apesar de sua ampla extensão e notável importância como recurso hídrico, as suas características hidráulicas são pouco conhecidas.

Os parâmetros hidrodinâmicos representam as propriedades físicas do meio que governam a circulação e o armazenamento destas águas e, consequentemente, condicionam o volume de água armazenado e a vazão máxima que pode ser extraída dos reservatórios. Estes parâmetros podem ser obtidos a partir de testes de bombeamento, que consistem no bombeamento de um poço com vazão constante e, simultaneamente, acompanhar a evolução do rebaixamento em um ou mais poços de observação.

$\mathrm{O}$ teste de bombeamento constitui, portanto, uma importante ferramenta para avaliar e determinar os parâmetros hidráulicos do aquífero. O emprego desses testes possibilita definir com relativa exatidão os parâmetros hidráulicos de transmissividade, condutividade hidráulica (horizontal e vertical) e o coeficiente de armazenamento (coeficiente de armazenamento) do aquífero.

A interpretação do teste de bombeamento requer o ajuste de uma determinada solução aos dados de rebaixamento. Tendo em vista que cada solução congrega um conjunto de premissas válidas para problemas específicos, o simples ajuste permite identificar o regime de fluxo imperante no aquífero testado. A despeito de sua potencialidade, os testes de bombeamento comumente são ajustados com o emprego solução de Theis (1935) ou Cooper-Jacob (1946) para aquíferos confinados em trechos retilíneos da curva do teste. A análise cautelosa do contexto hidrogeológico do aquífero testado pode revelar que as premissas presentes nas soluções de Theis (1935) ou Cooper-Jacob (1946) podem não se adequar integralmente ao problema estudado, de maneira que os parâmetros hidrodinâmicos determinados por esses métodos podem não ser representativos para o aquífero.

É relevante destacar que na maioria dos ensaios, apenas os dados de rebaixamento do poço bombeado estão disponíveis. E, nestas condições, mais de uma solução pode se ajustar à curva do 
teste e gerar ambiguidade nas interpretações. Assim, no intuito de evitar tal ambiguidade é ideal que um poço de observação seja monitorado durante a execução do ensaio e a solução escolhida se ajuste, simultaneamente, aos dois poços.

Além de dois poços de observação, a análise derivativa da curva do teste de bombeamento pode ser aplicada para eliminar esta ambiguidade, uma vez que permite diagnosticar o regime de fluxo imperante e as condições de contorno do aquífero. A gestão dos recursos hídricos subterrâneos requer o conhecimento pleno das características hidráulicas do aquífero, mensuração da quantidade de água armazenada e passível de explotação, assim como o regime de fluxo que governa a circulação de água no meio poroso. Tais estimativas podem ser subsidiadas por testes de bombeamento, que em muitas circunstâncias são interpretados de maneira equivocada.

Diante do cenário aqui descrito, o objetivo deste trabalho foi demonstrar a necessidade de se monitorar dois ou mais poços durante a execução dos testes de bombeamento, bem como avaliar aplicabilidade das técnicas derivativas em problemas complexos. A partir da abordagem aqui proposta é possível identificar o modelo conceitual que melhor se ajusta ao problema estudado, implicando em um aprimoramento do entendimento do Aquífero Serra Geral.

\section{CARACTERIZAÇÃO DA ÁREA}

\subsection{Localização}

A área de estudo está localizada na região do Triângulo Mineiro, porção leste do município de Campina Verde, Estado de Minas Gerais, (Figura 1). A sede municipal possui as coordenadas geográficas centradas em: 19³2'12" de latitude sul e 49²9'12" de longitude oeste.

O município possui uma área territorial de $3.650 \mathrm{~km}^{2}$ e, segundo o censo demográfico de 2014, a população total é de 20.022 habitantes, dos quais aproximadamente 70\% (14.015 habitantes) concentram-se na área urbana do município (IBGE 2014). 


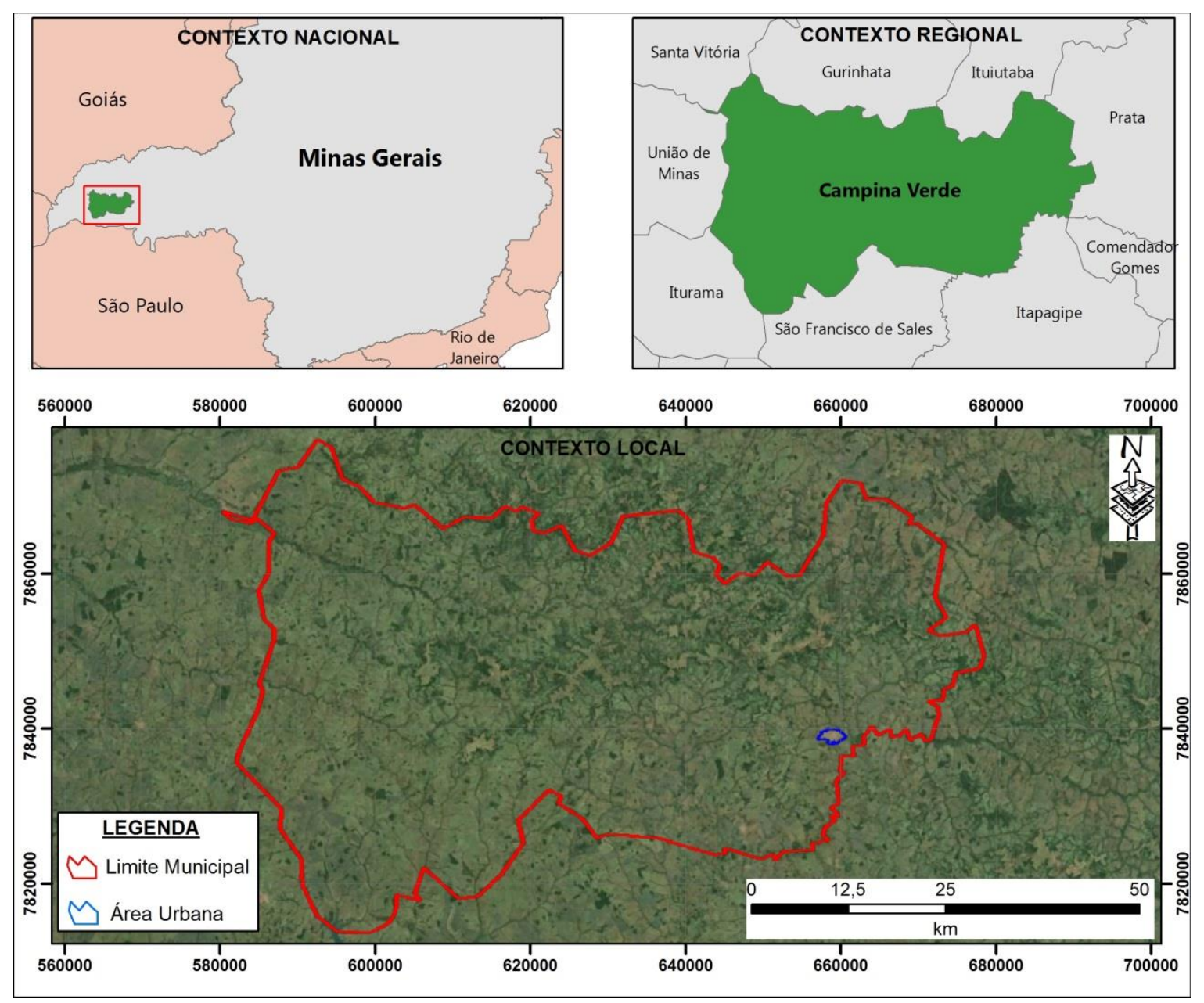

Figura 1 - Localização da área de estudo.

\subsection{Contexto Geológico}

Regionalmente o município de Campina Verde está inserido no contexto geológico da bacia do Paraná e abrange as formações Vale do Rio do Peixe e Marília, pertencentes ao Grupo Bauru, e os basaltos da Formação Serra Geral (Figura 2). Os testes de bombeamentos foram realizados em poços perfurados nos basaltos da Formação Serra Geral, conforme verificado nos perfis litológicos e em afloramentos nas proximidades dos poços. 


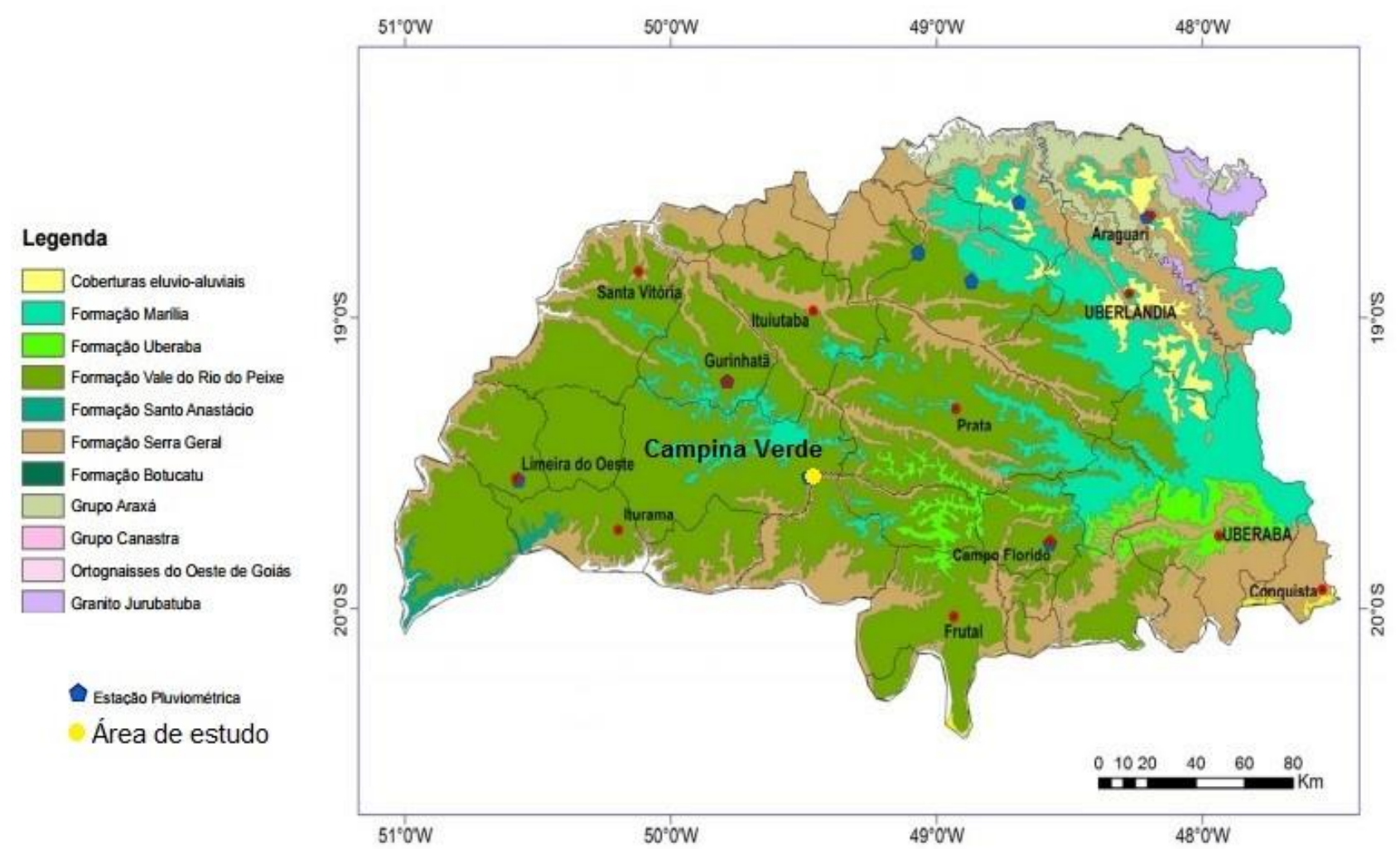

Figura 2 - Mapa geológico esquemático para o Triângulo Mineiro - Fonte: CPRM (2004a e 2004b).

A Formação Serra Geral pertence à Província Magmática do Paraná (PMP) é composta por uma sequência de derrames basálticos de idade jurássica-cretácica, que eventualmente encontram-se associados a arenitos intertrapeanos, e podem atingir até 2.000 metros de espessura (CORDANI \& VANDOROS, 1967). De modo geral, as rochas que compõem tal unidade são basaltos toleíticos e andesitos basálticos, com quantidades subordinadas de riolitos e riodacitos (PEATE et al., 1992).

Leinz (1949) descreveu um zoneamento vertical das fáceis que ocorrem em cada derrame basáltico, subdividindo-o em três porções: 1) base - composta por vidro e basalto fraturado horizontalmente; 2) porção central - com fraturas verticais de origem ligada ao resfriamento; e 3) topo - zona de fratura horizontal superposta pela zona vesicular amigdaloidal, as quais podem estar preenchidas por quartzo, calcita, zeólitas ou fluorita.

$\mathrm{Na}$ área e nas proximidades dos poços desse estudo foram observados afloramentos que apresentam tais feições, conforme mostra a foto da Figura 3. 


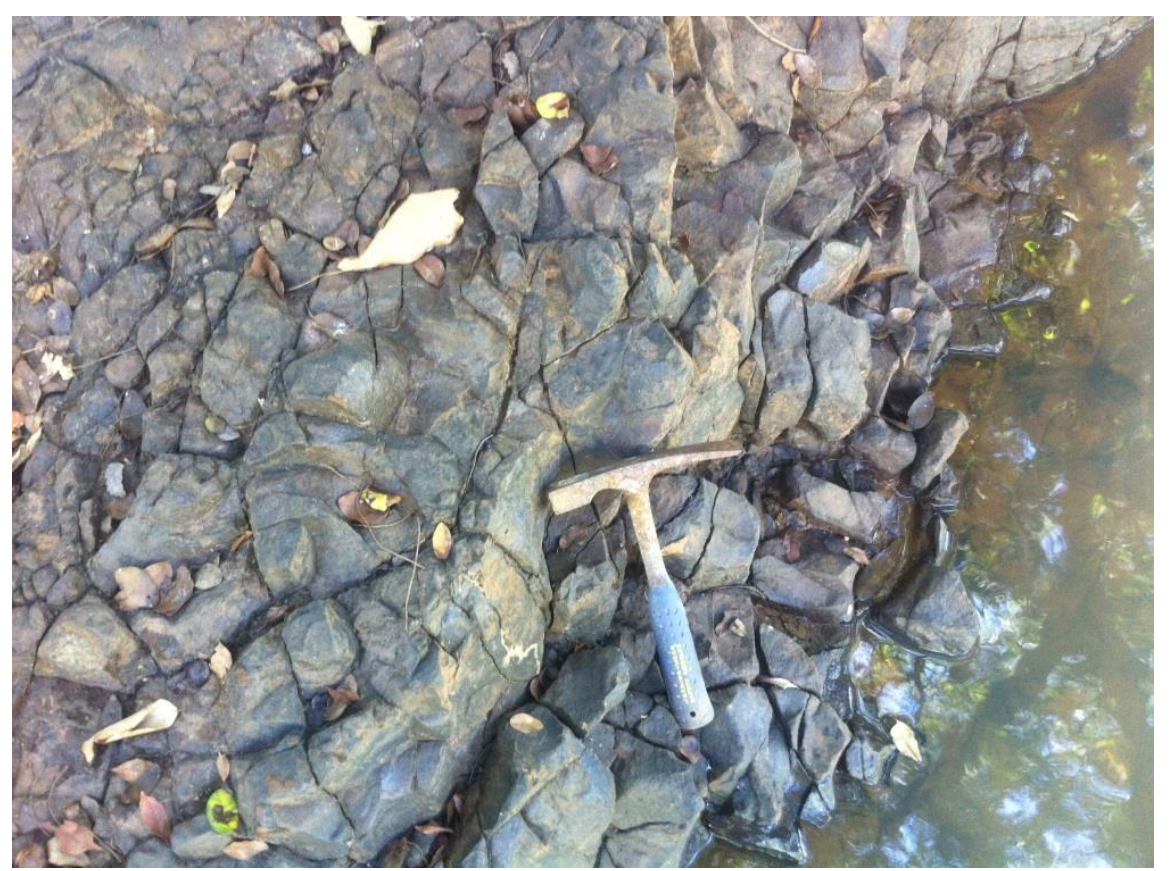

Figura 3 - Afloramento de basalto entablado às margens do Rio Verde. Os derrames de basaltos com fraturas e juntas são abundantes em toda a área.

Essas feições de entablamento em derrames basálticos da Bacia do Paraná também foram descritas por Souza Jr. (1992) e Gomes e Rodrigues (1999) em vários municípios paulistas, incluindo Ribeirão Preto, São Carlos e Araraquara. O entablamento é causado por resfriamento extremamente rápido que requer correntes de convecção da água ao longo das primeiras fraturas geradas (LONG \& WOOD, 1986).

\subsection{Hidrogeologia}

A área objeto deste estudo assenta-se sobre o Sistema Aquífero Serra Geral (SASG), cuja dinâmica de circulação de água nos basaltos está diretamente relacionada com os sistemas de descontinuidades nos derrames basálticos. Essas descontinuidades estão associadas às estruturas tectônicas (fraturas e falhas) e, principalmente, as estruturas atectônicas como as interfaces dos diferentes eventos de derrame basáltico (LASTORIA, 2002). O aquífero é, portanto, do tipo fraturado e anisotrópico com grande variabilidade dos parâmetros hidrodinâmicos e dimensionais.

O fluxo das águas subterrâneas nos derrames de basalto da Bacia do Paraná tem sido debatido por vários autores, dos quais se destaca Hausmann (1974), o qual considera que o fluxo das águas neste tipo de aquífero é condicionado pelo padrão de disjunção e, em geral, são as juntas verticais que possibilitam uma circulação livre devido a ação da gravidade. 
Bagolini (1971) admite que estas descontinuidades horizontais teriam sua origem ligada ao fluxo diferencial na base dos derrames, devido ao resfriamento diferencial do magma gerando as superfícies de atrito nesta porção do derrame. Na zona intermediária o sistema de descontinuidades é predominantemente vertical, representado por diaclases, com feição pseudo-colunar, enquanto que na porção superior do derrame ocorrem as estruturas associadas ao escape de gases, com aspecto vesicular escoriáceo, e diaclasamento horizontal.

Rebouças e Fraga (1988) expõem um modelo geral para o comportamento hidrogeológico destes aquíferos, dividindo-o em duas unidades: superior, composta pelo resultado da alteração intempérica do basalto, tendo na base uma superfície de descontinuidade física que representaria uma zona de alta permeabilidade; e a unidade inferior, localizada abaixo desta continuidade, tendo sido considerada como zona preferencial de circulação de água. Esta unidade caracteriza-se pela ocorrência de vesículas e pelo intenso faturamento horizontal, com a circulação vertical incidindo nas diaclases da porção central do derrame.

\section{MATERIAIS E MÉTODOS}

\subsection{Testes de bombeamento}

O teste realizado no município de Campina Verde foi de 24 horas de bombeamento contínuo, com medição da vazão e rebaixamento ao longo do tempo. Buscando aprimorar o teste aqui descrito, também foi monitorado o nível dinâmino de um poço de observação (P2) situado a 58 metros do poço de bombeamento, a fim de registrar possíveis interferências que o mesmo pudesse sofrer durante toda a execução do ensaio.

Antes de executar o teste de bombeamento, os poços testados permaneceram desligados por um período de 6 horas para recuperação do nível estático. Durante o teste, o rebaixamento foi medido utilizando-se de um medidor elétrico graduado de nível d'água e a vazão do poço foi periodicamente mensurada com auxilio de um tambor de 200 litros (Figuras 4 e 5), de modo a avaliar as variações de vazão ao longo do teste. Após um período de 24 horas de teste o bombeamento foi interrompido, e a recuperação do nível nos poços foi monitorada até a estabilização do nível d'água. 


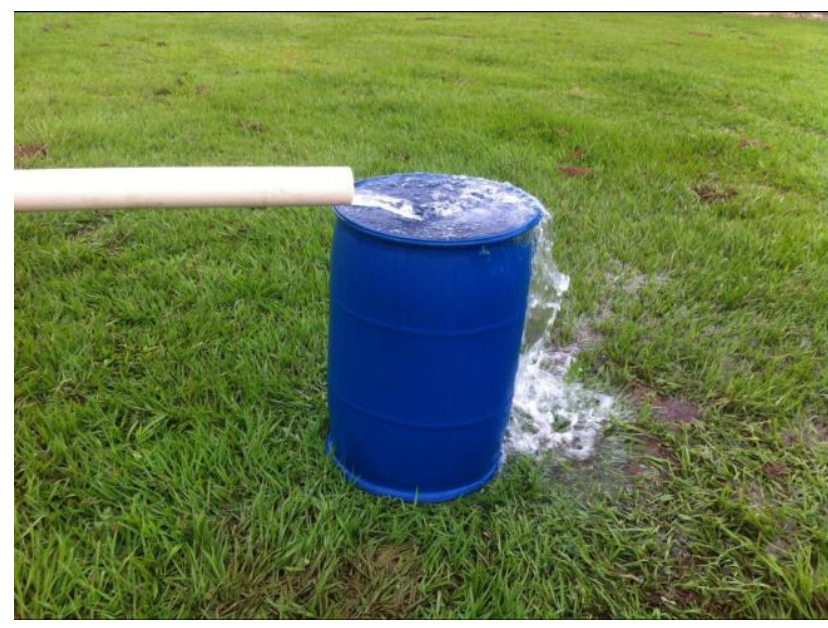

Figura 4 - Medição da vazão com auxilio de um tambor de 200 litros.

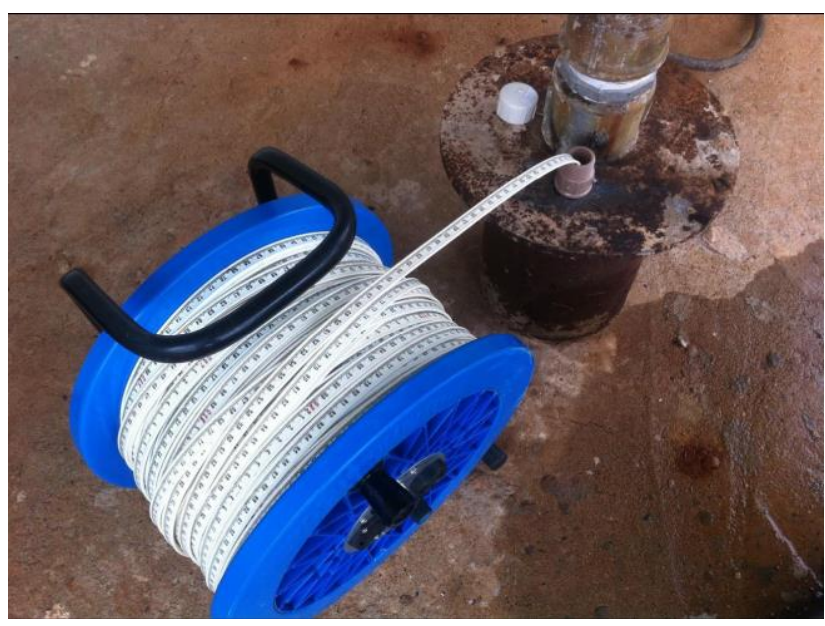

Figura 5 - Medição do rebaixamento do nível d’água com o auxílio de um medidor de nível.

\subsection{Interpretação}

Considerando o contexto geológico onde foi realizado o teste de bombeamento, (rochas efusivas básicas da Formação Serra Geral), diversos ajustes foram sucessivamente testados e avaliados, empregando-se o aplicativo AQTESOLV. O software Aqtesolv, selecionado para a interpretação dos testes de bombeamento, permite a interpretação por meio da curva de rebaixamento e da análise derivativa. $\mathrm{O}$ cálculo da curva derivativa é realizado empregando-se a metodologia de Bourdet et al. (1989), que aproxima a derivada da curva de rebaixamento por meio da equação 1. Segundo esses autores, o formato da curva derivativa em gráficos monolog e log-log é extremamente sensível às pequenas variações do rebaixamento e sua análise permite detectar variações de difícil percepção pela análise gráfica clássica e realizar o diagnóstico do modelo conceitual para interpretação do teste.

$$
\left(\frac{\partial s}{\partial \ln t}\right)=\frac{\left(\frac{\partial s_{i-1}}{\partial \ln t_{i-1}}\right) \Delta \ln t_{i+1}+\left(\frac{\partial s_{i+1}}{\partial \ln t_{i+1}}\right) \Delta \ln t_{i-1}}{\Delta \ln t_{i-1}+\Delta \ln t_{i+1}}
$$

Além de determinar parâmetros hidrodinâmicos, os testes de bombeamento permitem avaliar se um conjunto de premissas presente na solução selecionada é válido para o aquífero estudado, e, consequentemente, organizar modelos conceituais consistentes. Para demonstrar a aplicabilidade dos testes de bombeamento como subsídio à elaboração de modelos hidrogeológicos conceituais, empregou-se os resultados dos mesmos na interpretação do regime de fluxo local. O principal 
critério para interpretação dos testes foi a adequação da solução testada a análise da curva de rebaixamento e derivativa dos poços de bombeamento e de observação.

Uma vez testadas todas as opções viáveis para o contexto geológico, foi possível identificar a solução e o conjunto de premissas que descrevem de maneira mais fidedigna o regime de fluxo na área de estudo. Adotando-se como referência o conhecimento geológico prévio foi construído um modelo geológico conceitual que descreve o regime de fluxo local. Por fim, este modelo conceitual foi comparado com outros modelos conceituais elaborados em contextos geológicos similares.

\section{RESULTADOS}

Na Tabela 1 estão os resultados obtidos ao longo das 24 horas de bombeamento, bem como a recuperação do nível após ter cessado o bombeamento.

Tabela 1 - Dados do teste de bombeamento.

\begin{tabular}{|c|c|c|c|c|c|}
\hline \multicolumn{3}{|c|}{ Poço 1 (BOMBEANDO) } & \multirow{2}{*}{ Tempo } & \multicolumn{2}{|c|}{ Poço 2 (MONITORANDO) } \\
\hline \multirow{2}{*}{$\begin{array}{c}\text { Vazão } \\
\text { (litros/hora) }\end{array}$} & Rebaixamento & Recuperação & & Rebaixamento & Recuperação \\
\hline & $\begin{array}{l}\text { Profundidade do } \\
\text { nível d'água (m) }\end{array}$ & $\begin{array}{l}\text { Profundidade do } \\
\text { nível d'água (m) }\end{array}$ & (minutos) & $\begin{array}{l}\text { Profundidade do } \\
\text { nível d'água (m) }\end{array}$ & $\begin{array}{l}\text { Profundidade do } \\
\text { nível d'água (m) }\end{array}$ \\
\hline 0 & 4,63 & 25,25 & 0 & 4,55 & 22,13 \\
\hline 14663,95 & 6,33 & 22,77 & 1 & 4,55 & 21,86 \\
\hline 14649,03 & 7,04 & 22,06 & 2 & 4,92 & 21,59 \\
\hline 14666,93 & 7,74 & 21,68 & 3 & 5,29 & 21,30 \\
\hline 14574,89 & 8,20 & 21,30 & 4 & 5,67 & 21,17 \\
\hline 14524,91 & 8,57 & 20,93 & 5 & 6,04 & 20,81 \\
\hline 14545,45 & 8,90 & 20,55 & 6 & 6,42 & 20,50 \\
\hline 14574,89 & 9,60 & 19,80 & 8 & 6,80 & 20,01 \\
\hline 14583,75 & 10,10 & 19,27 & 10 & 7,48 & 19,52 \\
\hline 14604,46 & 10,56 & 18,80 & 12 & 8,17 & 19,03 \\
\hline 14634,14 & 11,20 & 18,09 & 15 & 8,56 & 18,29 \\
\hline 14619,28 & 12,27 & 17,07 & 20 & 9,45 & 17,07 \\
\hline 14646,05 & 12,84 & 16,04 & 25 & 10,26 & 16,06 \\
\hline 14400,00 & 13,50 & 15,02 & 30 & 11,07 & 14,97 \\
\hline 14195,58 & 14,76 & 13,15 & 40 & 12,00 & 12,79 \\
\hline 13937,28 & 15,50 & 11,87 & 50 & 12,99 & 11,60 \\
\hline 13913,04 & 16,27 & 10,60 & 60 & 13,56 & 10,55 \\
\hline 13904,98 & 16,88 & 10,00 & 70 & 14,30 & 9,75 \\
\hline 13798,39 & 17,58 & 9,38 & 80 & 14,78 & 9,25 \\
\hline 13766,73 & 18,47 & 8,61 & 100 & 15,81 & 8,36 \\
\hline 13766,73 & 19,35 & 7,93 & 120 & 16,50 & 7,70 \\
\hline 13690,81 & 20,33 & 7,25 & 150 & 17,51 & 7,04 \\
\hline 13651,87 & 21,21 & 6,83 & 180 & 18,24 & 6,56 \\
\hline 13526,20 & 21,73 & 5,90 & 210 & 18,93 & 5,80 \\
\hline 13495,78 & 22,16 & 4,63 & 240 & 19,27 & 4,55 \\
\hline 13452,91 & 22,59 & & 270 & 19,61 & \\
\hline 13445,37 & 22,83 & & 300 & 19,97 & \\
\hline 13445,37 & 23,12 & & 330 & 20,19 & \\
\hline 13462,97 & 23,26 & & 360 & 20,38 & \\
\hline 13508,44 & 23,46 & & 390 & 20,53 & \\
\hline 13564,43 & 23,63 & & 420 & 20,71 & \\
\hline 13415,31 & 23,84 & & 480 & 20,94 & \\
\hline
\end{tabular}




\begin{tabular}{|l|l|l|l|l|l|}
\hline 13450,40 & 24,01 & & 540 & 21,08 & \\
\hline 13348,16 & 24,16 & & 600 & 21,22 & \\
\hline 13407,82 & 24,17 & & 660 & 21,11 & \\
\hline 13318,53 & 24,34 & & 720 & 21,11 & \\
\hline 13318,53 & 24,46 & & 780 & 21,30 & \\
\hline 13318,53 & 24,71 & & 840 & 21,40 & \\
\hline 13318,53 & 24,81 & & 900 & 21,63 & \\
\hline 13318,53 & 24,82 & & 960 & 21,73 & \\
\hline 13318,53 & 24,96 & & 1020 & 21,81 & \\
\hline 13318,53 & 25,11 & & 1080 & 21,89 & \\
\hline 13318,53 & 25,14 & & 1140 & 21,97 & \\
\hline 13318,53 & 25,19 & & 1200 & 22,03 & \\
\hline 13318,53 & 25,19 & & 1260 & 22,08 & \\
\hline 13318,53 & 25,23 & & 1320 & 22,10 & \\
\hline 13318,53 & 25,24 & & 1380 & 22,12 & \\
\hline 13318,53 & 25,25 & & 1440 & 22,13 & \\
\hline
\end{tabular}

$\mathrm{Na}$ Figura 6, em escala bi-logarítmica, são apresentados os resultados do rebaixamento registrado nos dois poços monitorados durante a execução do ensaio. É possível notar que o poço de observação responde de maneira instantânea com o início do bombeamento, seguindo uma tendência de queda do nível d'água paralelo ao observado no poço que foi efetivamente bombeado.

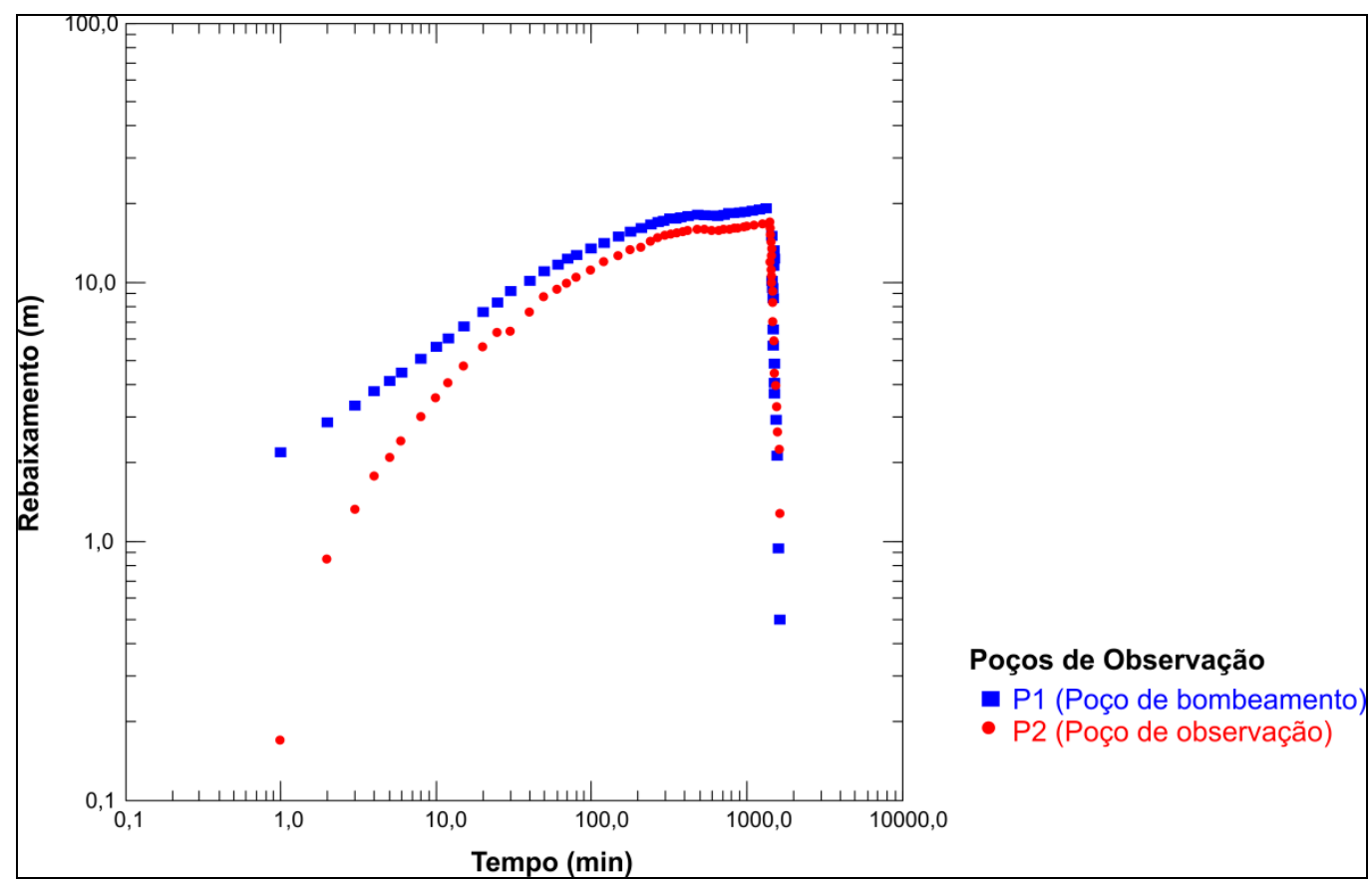

Figura 6 - Gráfico bi-logarítmico do rebaixamento em função do tempo para os poços P1 e P2.

A Figura 7 ilustra as variações de vazão ao longo de todo o teste. É possível notar uma queda no início do teste e posterior estabilização da vazão. Embora tenha tentado manter a vazão máxima constante, pequenas oscilações na vazão do bombeamento foram registradas, as quais podem ser decorrentes de variações na rotação da bomba (em razão da oscilação da corrente elétrica) ou representar efeitos da geometria do aquífero avaliado. 


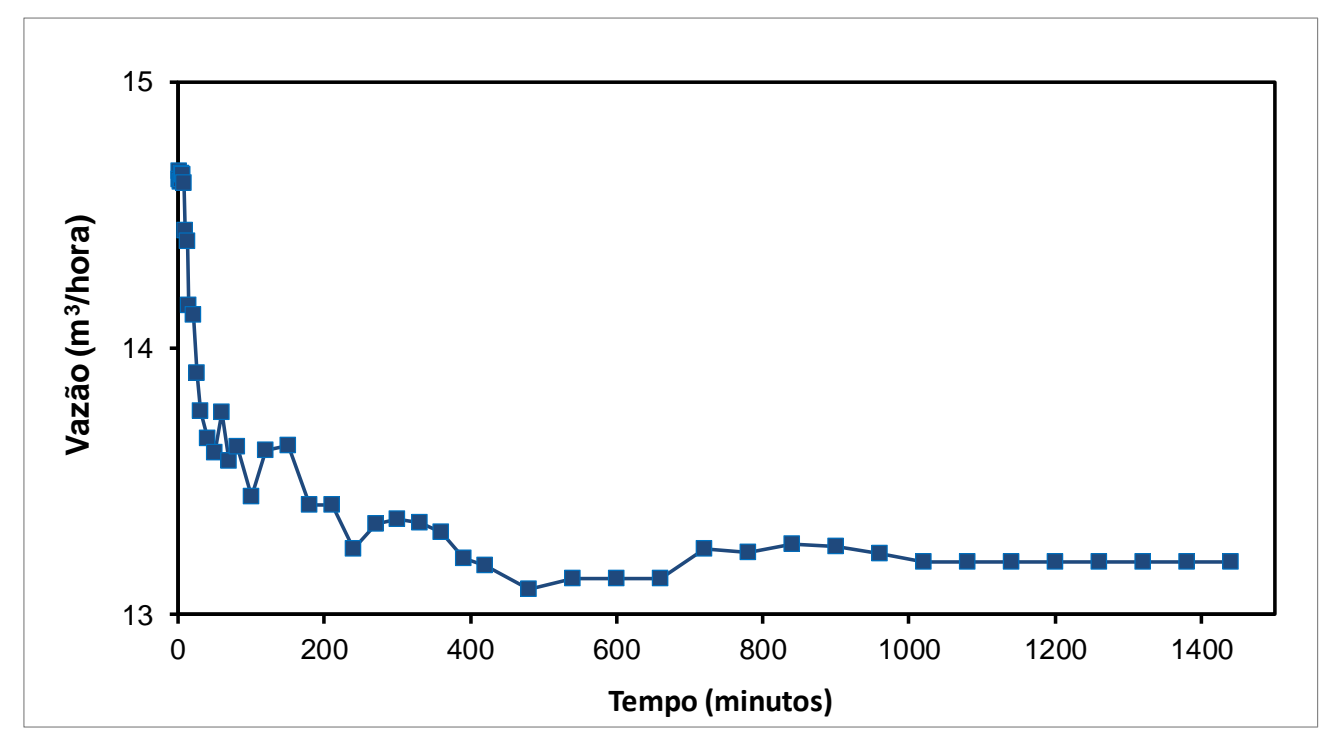

Figura 7 - Variações de vazão durante a execução do teste de bombeamento.

As Figuras 8 e 9 apresentam, respectivamente, os ajustes com a solução para aquíferos com uma única fratura vertical (GRINGARTEN \& WITHERSPPON, 1984) e aquífero com uma única fratura horizontal (GRINGATER ET AL, 1992). Ajustando-se o tamanho das fraturas e impondo-se uma condição de contorno de carga constante é possível ajustar ambas as curvas das soluções aos dados de rebaixamento do poço de bombeamento. Entretanto, não é possível ajustar simultaneamente o rebaixamento do poço de bombeamento (P1) e o poço de observação (P2), indicando que esta solução pode não ser válida para o problema estudado.

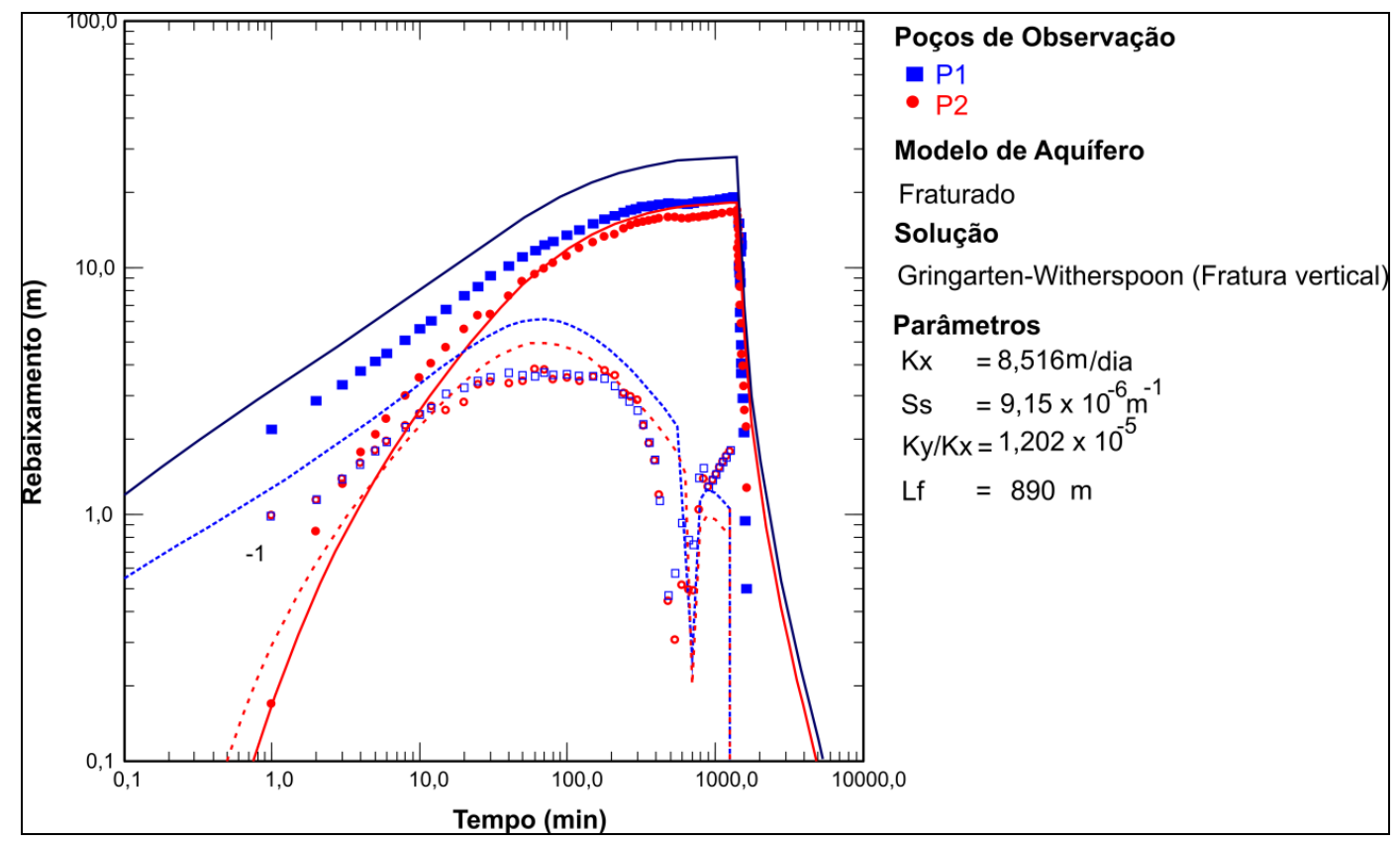

Figura 8 - Ajuste da solução de Gringarten-Whiterspoon (1974) aos dados de rebaixamento em

função do tempo. Esta solução foi desenvolvida para interpretação de ensaios em poços que interceptam fraturas verticais com extensão infinita. 


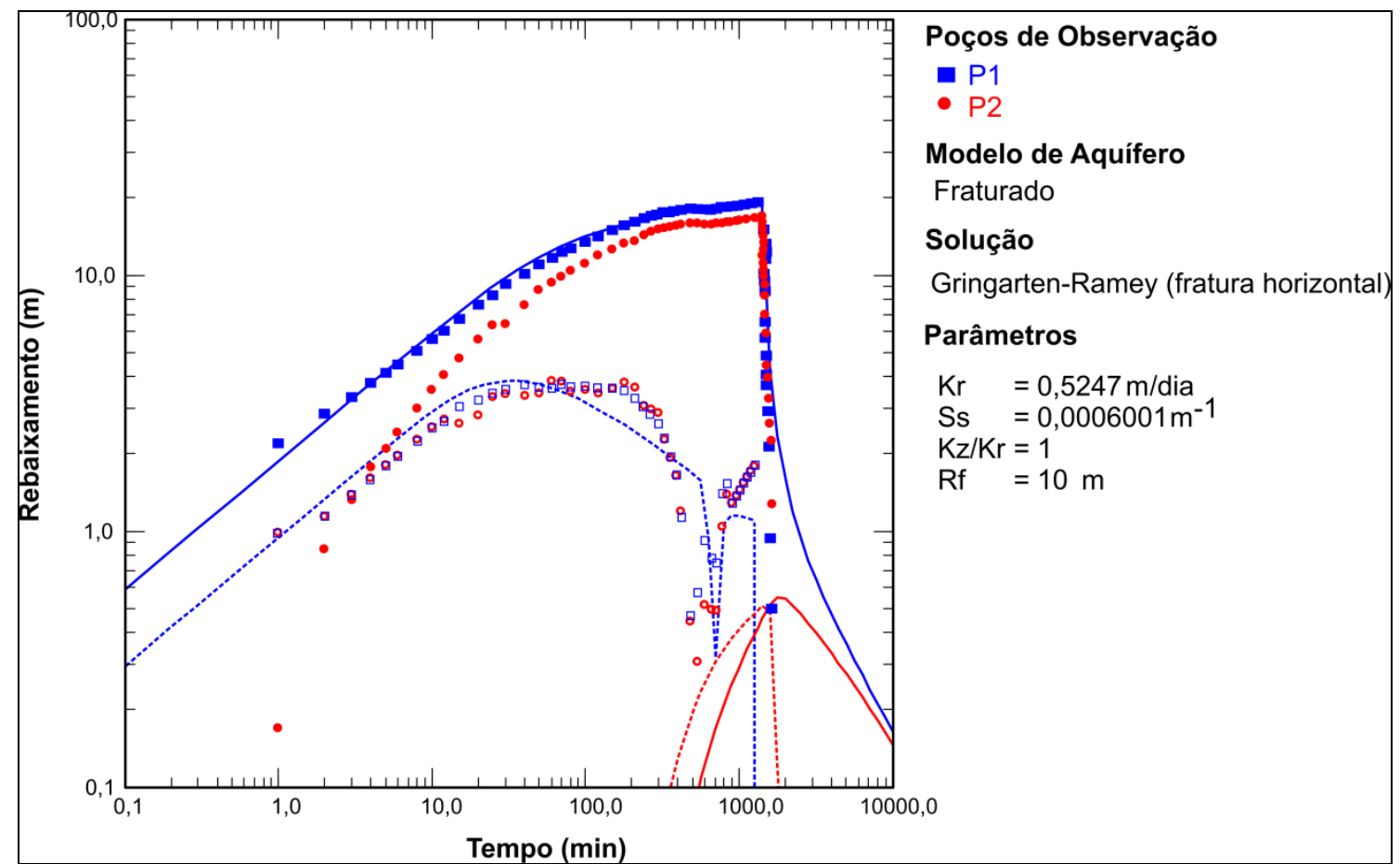

Figura 9 - Ajuste da solução de Gringarten-Ramey (1984) aos dados de rebaixamento em função do tempo. Esta solução foi desenvolvida para interpretação de ensaios em poços que interceptam fraturas horizontais com extensão infinita.

Segundo Khaleel (1989) os basaltos com diaclases geradas por stress durante o seu resfriamento podem ser aproximados como meio porosos equivalentes (MPE) quando grandes escalas são avaliadas. Sob essa premissa, foi testada a hipótese de que o aquífero poderia se comportar como um aquífero livre. Como é possível observar na Figura 10, o modelo de aquífero livre não se ajusta a nenhum dos poços monitorados, indicando que este modelo não reproduz conceitualmente o aquífero estudado. 


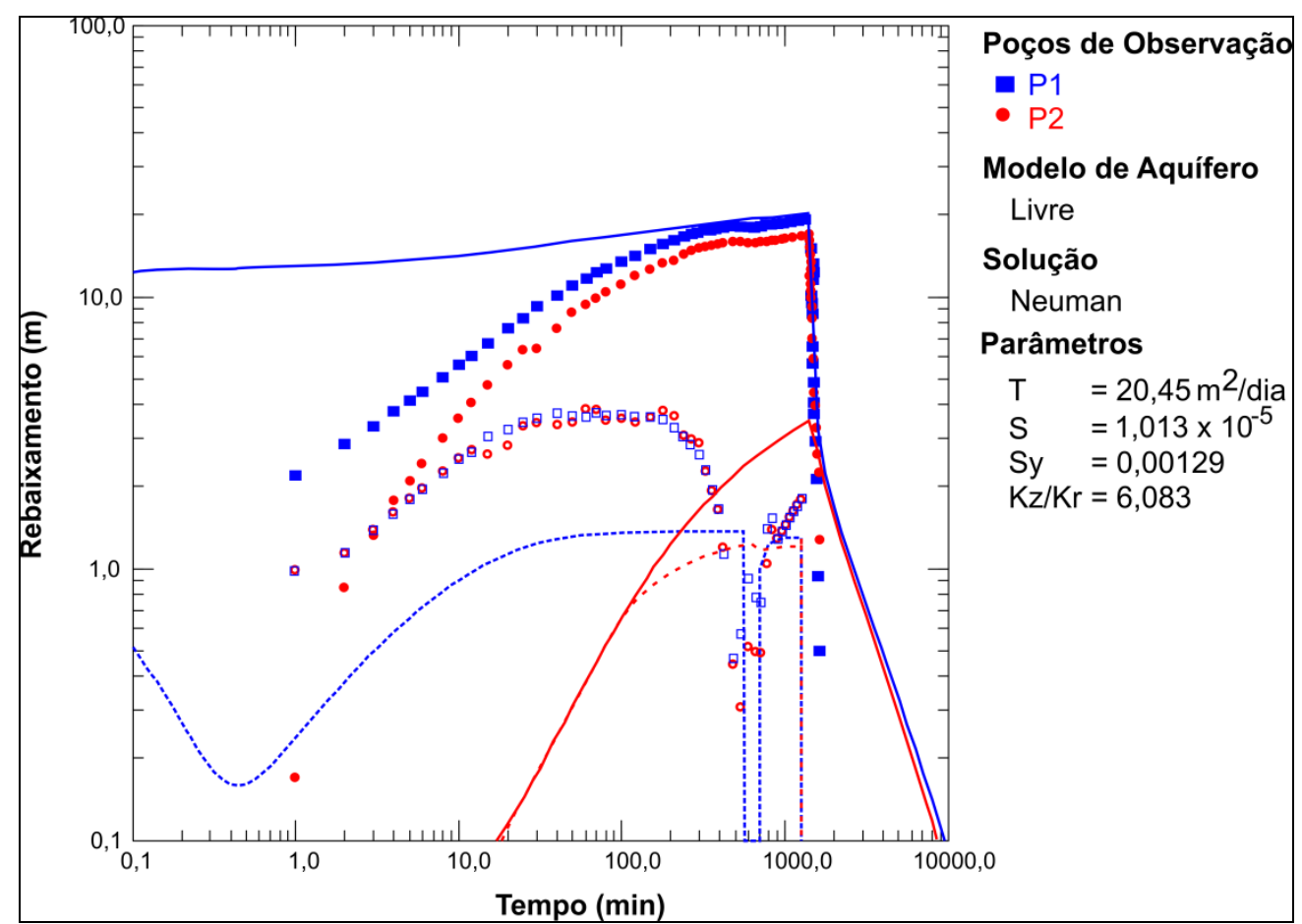

Figura 10 - Ajuste da solução de Neuman (1969) aos dados de rebaixamento em função do tempo. Esta solução foi desenvolvida para interpretação de ensaios em aquíferos livres.

O modelo de dupla porosidade de Moench (1984) assume a existência de fluxo em conjunto de poros distintos: a primeira representada pelas fraturas e segunda pela matriz dos blocos rochosos. Como é possível observar na Figura 11, se apenas os dados de rebaixamento do poço de bombeamento estivessem disponíveis, a solução de Moench (1984) teria sido considerada satisfatória, similarmente à condição observada nas soluções de Gringarten \& Withersppon (1984) para aquíferos representado por uma única fratura vertical e aquífero representado por uma única fratura horizontal Gringater et al (1992). Esta constatação reforça a necessidade de se empregar poços de observação adicionais para evitar interpretações equivocadas do regime de fluxo do aquífero testado. 


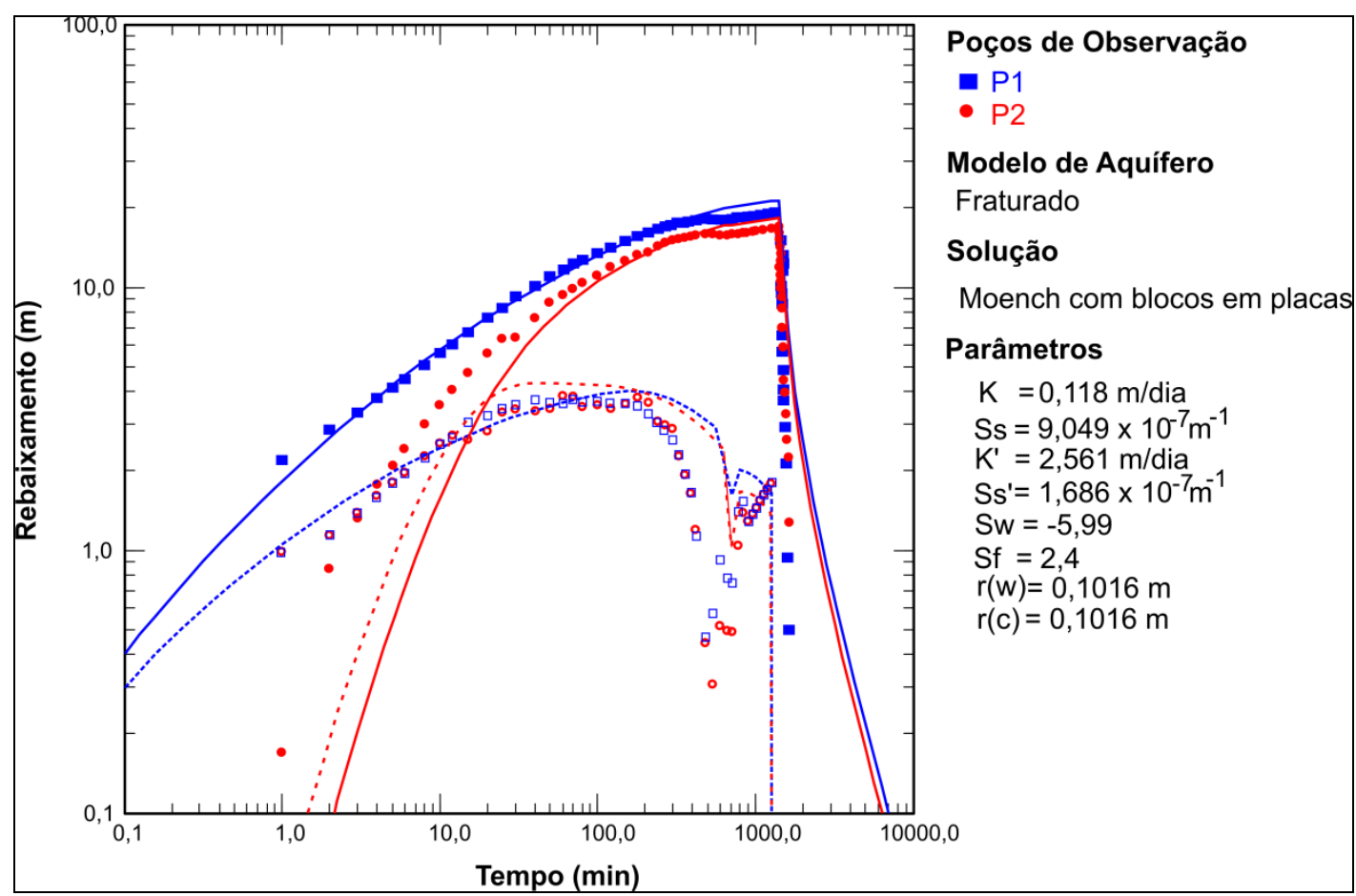

Figura 11 - Ajuste da solução de Moench (1984) aos dados de rebaixamento em função do tempo.

Esta solução foi desenvolvida para interpretação de ensaios com dupla porosidade.

Das soluções testadas, a única solução que se ajustou de maneira satisfatória e simultânea aos dois poços monitorados durante o teste de bombeamento foi o modelo para aquíferos confinados drenantes, proposto por Moench (1985). Gingerich (1999) e Hamm et al (2005), interpretando testes de bombeamento em outros aquíferos basálticos demonstraram que a solução de Moench (1985) é a mais apropriada. As premissas adotadas por Moench (1985) requerem que o aquífero testado seja confinado no topo e na base por unidades de baixa permeabilidade com drenança vertical.

Tendo em vista as suas características genéticas, basaltos representam sistemas aquíferos que alternam intervalos com condutividade hidráulica muito elevada com intervalos de condutividade hidráulica reduzida (LUZIER \& BURT, 1974; LONG \& WOOD, 1986; KULKARNI ET AL, 2000; MCGRAIL ET AL, 2006). A alternância de camadas com características hidráulicas distintas faz com que os basaltos representem aquíferos multicamadas, podendo ser satisfatoriamente descritas pelas premissas assumidas pelo modelo de Moench (1985).

Neste tipo de cenário, é esperado que as camadas com elevada permeabilidade sejam confinadas por camadas pouco permeáveis no topo, embora a presença de diaclases geradas pelos processos de resfriamento permita a drenança de água das unidades mais rasas para a unidade aquífera confinada. 


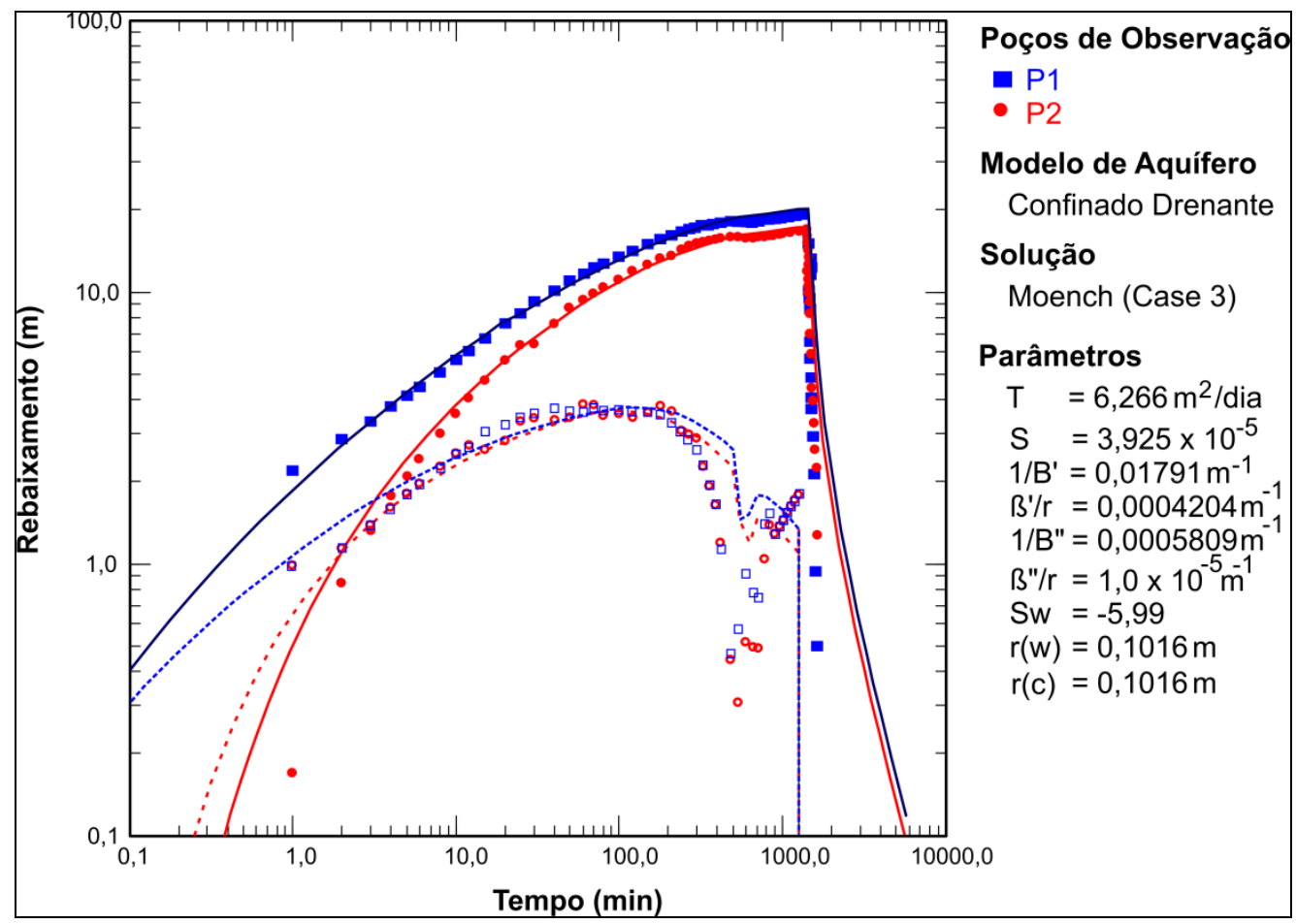

Figura 11 - Ajuste da solução de Moench (1985) aos dados de rebaixamento em função do tempo. Esta solução foi desenvolvida para interpretação de ensaios em aquíferos confinados delimitados no topo e na base por unidades drenantes.

\section{CONCLUSÕES}

Considerando o exposto ao longo do presente trabalho, conclui-se que é necessário adotar cautela na interpretação dos testes de bombeamento mesmo quando apenas os dados de rebaixamento e recuperação dos poços bombeados estão disponíveis. Embora dificilmente estejam disponíveis, os poços de observação são de fundamental importância para interpretação dos testes, uma vez que restringem o número de soluções que podem ser ajustadas.

Foi possível observar que o aquífero objeto deste estudo é caracterizado por unidades de baixa permeabilidade no topo e na base, além de apresentar uma drenança vertical, configurando um aquífero confinado drenante, condição que pode ser comum neste tipo de aquífero.

Embora não represente uma prática comum, o emprego de análises derivativas representou uma etapa essencial na interpretação dos testes de bombeamento, uma vez que permitiu diagnosticar o modelo hidrogeológico conceitual mais adequado à curva de rebaixamento obtida pelo teste. Esta análise é muito sensível às variações de vazão decorrentes na oscilação da vazão de bombeamento, tornando necessário o controle rigoroso das vazões durante a execução do teste. 


\section{REFERÊNCIAS BIBLIOGRÁFICAS}

BAGOLINI, B. Osservazioni geologiche e geomorfologiche sugli espandimenti basaltici del Bacino dell'Alto Paraná nel Brasile Meridionale. Museo Tridentino de Science Naturali. Trento, Itália, p. 69-119, 1971.

BJORNBERG, A. J. S. KUTNER, A. S. Resumo das feições geológicas de interesse às fundações em rocha, em barragens da Bacia do Alto Paraná. In: SIMPÓSIO SOBRE A GEOTECNIA DA BACIA DO ALTO PARANÁ, 1983, São Paulo. Anais São Paulo: ABMS/ABGE/CBMR, 1983. v. 1A, p. 263-297.

BOURDET, D. AYOUB, J. A. AND PIRARD, Y. M. Use of Pressure Derivative in Well-Test Interpretation. In: SPEFE p. 293-302, 1989.

COOPER, H. H.; JACOB, C. E. A generalized graphical method for evaluating formation constants and summarizing well-field history. Eos, Transactions American Geophysical Union, v. 27, n. 4, p. 526-534, 1946.

CORDANI, U. G.; VANDOROS, P. Basaltics rocks of the Paraná Basin: Problems in Brazilian gondwana geology. Plate LXXVIII, CNPq, Boletim Paranaense de Geografia. Curitiba, v.21 (22): 207-231, 1967.

GINGERICH, S. B. Estimating transmissivity and storage properties from aquifer tests in the southern Lihue basin, Kauai, Hawaii. US Department of the Interior, US Geological Survey, 1999.

GOMES, R. L. G.; RODRIGUES, J. E. Reconhecimento dos diferentes tipos de derrames basálticos segundo a compartimentação entablamento-colunata em algumas pedreiras do Estado de São Paulo. In: CONGRESSO BRASILEIRO DE GEOLOGIA DE ENGENHARIA, 9, 1999. São Pedro. Panorama da Geologia de Engenharia... São Paulo: ABGE, 1999.

GRINGARTEN, A. C.; RAMEY J. R, H. J.; RAGHAVAN, R. Unsteady-state pressure distributions created by a well with a single horizontal fracture, partial penetration, or restricted entry. Society of petroleum engineers journal, v. 14, n. 04, p. 413-426, 1974.

GRINGARTEN, A.C.; WITHERSPOON, P.A., A Method of Analyzing Pump Test Data from Fractured Aquifers, Symposium of Percolation Through Fissured Rock, Int. Soc. Rock. Mech. / Int. Assoc. Eng. Geol., Stuttgard, vol. 3B, p. 1-9, 1972.

HAMM, S-Y.; Cheong, J. Y., Jang, S., Jung, C. Y., Kim, B. S. Relationship between transmissivity and specific capacity in the volcanic aquifer of Jeju Island, Korea. Journal of Hydrology, V. 310, p 111-121. 2005.

HAUSMAN, A. Aspectos hidrogeológicos dos aquíferos fissurados no sul da Bacia do Paraná. Revista Água Subterrânea. São Paulo, v.1(4): 44-60, 1974. 
JENKINS, David N.; PRENTICE, John K. Theory for aquifer test analysis in fractured rocks under linear (nonradial) flow conditions. Ground Water, v. 20, n. 1, p. 12-21, 1982.

KHALEEL, R. Scale dependence of continuum models for fractured basalts. Water Resources Research, v. 25, n. 8, p. 1847-1855, 1989.

KULKARNI, Himanshu et al. Hydrogeological framework of the Deccan basalt groundwater systems, west-central India. Hydrogeology Journal, v. 8, n. 4, p. 368-378, 2000.

LASTORIA, G. Hidrogeologia da Formação Serra Geral no Estado de Mato Grosso do Sul. Rio Claro, 2002. 133 p. Tese (Doutoramento em Geociências e Meio Ambiente). Instituto de Geociências e Ciências Exatas - IGCE - UNESP - Rio Claro, 2002.

LEINZ, V. Contribuição à geologia dos derrames basálticos do sul do Brasil. Boletim FFCHL-USP. Geologia, v. 103, n. 5, p. 1-103, 1949.

LEINZ, V.; BARTORELli, A.; SADOWSKI, G. R.; ISOTTA, C. A. L. Sobre o comportamento espacial do Trapp basáltico da Bacia do Paraná. Boletim da SBG, v. 15, n. 4, p. 79-91, 1966.

LINDBERG, J. W. A numerical study of cooling joint width and secondary mineral infilling in four Grande Ronde Basalt flows of the central Columbia Plateau, Washington. Geological Society of America Special Papers, v. 239, p. 169-186, 1989.

LONG, P. E.; WOOD, B. J. Structures, textures, and cooling histories of Columbia River basalt flows. Geological Society of America Bulletin, v. 97, n. 9, p. 1144-1155, 1986.

LUZIER, J. E.; BURT, R. J. Hydrology of basalt aquifers and depletion of ground water in eastcentral Washington. 1974.

MOENCH, A.F. Transient Flow to a Large-Diameter Well in an Aquifer With Storative Semiconfining Layers. Water Resources Research, v. 21, n. 8, p. 1121-1131, 1985.

NARDY, A. J. R.; OLIVEIRA, M. A. F.; BETANCOURT, R. H. S.; VERDUGO, D. R. H.; MACHADO, F. B. Geologia e estratigrafia da Formação Serra geral. Geociências, v. 21, n. 1-2, p. 13-30, 2002.

NEUMAN, S. P.; WITHERSPOON, P. A. Theory of flow in a confined two aquifer system. Water Resources Research, v. 5, n. 4, p. 803-816, 1969.

PEATE D.W., HAWKESWORTH J.C., MANTOVANI M.S.M. Chemical stratigraphy of theParaná lavas (South America): classification of magmas types and their spatial distribution, Bull. Volcanol. 55. 1992. 119-139p.

REBOUÇAS A.C.; FRAGA C.G. Hidrogeologia das rochas vulcânicas do Brasil. Revista de Águas Subterrâneas, ABAS, 12:29-55. 1988

SINELLI, O. Água subterrânea no município de Ribeirão Preto. In: CONGRESSO BRASILEIRO DE GEOLOGIA, 25. 1971, São Paulo. Anais. São Paulo: SBG, p. 17-34, 1971a. 
SOUZA JUNIOR, N. N. O "entablamento" em derrames basálticos da Bacia do Paraná: aspectos genéticos e caracterização geotécnica. 1992. 257 f. Tese (Doutorado) - Escola de Engenharia de São Carlos, Universidade de São Paulo, São Carlos, 1992.

THEIS, C. V. The relation between the lowering of the Piezometric surface and the rate and duration of discharge of a well using ground-water storage. Eos, Transactions American Geophysical Union, v. 16, n. 2, p. 519-524, 1935.

TOMKEIEFF, S. I. The basalt lavas of the Giant's Causeway district of Northern Ireland. Bulletin Volcanologique, v. 6, n. 1, p. 89-143, 1940.

UHL, V. W.; JOSHI, V. G. Results of pumping tests in the Deccan trap basalts of central India. Journal of Hydrology, v. 86, n. 1, p. 147-168, 1986.

WHITEHEAD, R. L. Geohydrologic framework of the Snake River Plain regional aquifer system, Idaho and eastern Oregon. US Government Printing Office, 1992. 